\title{
Soil Organic Carbon and Its Fractions Across Vegetation Types: Effects of Soil Mineral Surface Area and Microaggregates*1
}

\author{
WU Qing-Biao ${ }^{1,2}$, WANG Xiao-Ke ${ }^{2, * 2}$ and OUYANG Zhi-Yun ${ }^{2}$ \\ ${ }^{1}$ Forestry College of Guangxi University, Nanning 530004 (China). E-mail: wuqb2003@yahoo.com.cn \\ ${ }^{2}$ Research Center for Eco-Environmental Sciences, Chinese Academy of Sciences, Beijing 100085 (China) \\ (Received July 28, 2008; revised January 19, 2009)
}

\begin{abstract}
Soil organic carbon (SOC) can act as a sink or source of atmospheric carbon dioxide; therefore, it is important to understand the amount and composition of SOC in terrestrial ecosystems, the spatial variation in SOC, and the underlying mechanisms that stabilize SOC. In this study, density fractionation and acid hydrolysis were used to assess the spatial variation in SOC, the heavy fraction of organic carbon (HFOC), and the resistant organic carbon (ROC) in soils of the southern Hulun Buir region, northeastern China, and to identify the major factors that contribute to this variation. The results showed that as the contents of clay and silt particles $(0-50 \mu \mathrm{m})$ increased, both methylene blue (MB) adsorption by soil minerals and microaggregate contents increased in the $0-20$ and $20-40 \mathrm{~cm}$ soil layers $(P<0.05)$. Although varying with vegetation types, SOC, HFOC, and ROC contents increased significantly with the content of clay and silt particles, MB adsorption by soil minerals, and microaggregate content $(P<0.05)$, suggesting that soil texture, the MB adsorption by soil minerals, and microaggregate abundance might be important factors influencing the spatial heterogeneity of carbon contents in soils of the southern Hulun Buir region.
\end{abstract}

Key Words: carbon fractions, microaggregates, soil mineral surface area, soil organic carbon, vegetation

Citation: Wu, Q. B., Wang, X. K. and Ouyang, Z. Y. 2009. Soil organic carbon and its fractions across vegetation types: Effects of soil mineral surface area and microaggregates. Pedosphere. 19(2): 258-264.

\section{INTRODUCTION}

The Kyoto Protocol has drawn attention to terrestrial ecosystems as potential sinks for atmospheric carbon dioxide (O'Brien et al., 2003). Because soils contain nearly twice as much carbon (C) as the vegetation, a better understanding of soil organic carbon (SOC) distribution and its stabilization mechanisms is important (Mann, 1986). Soil organic matter is often categorized into physico-chemically protected fractions, such as organo-mineral particles, and the occluded particulate organic matter in microaggregates, biochemically protected fractions, such as recalcitrant soil organic matter (SOM) compounds, and free particulate organic matter (Six et al., 2002; Peng et al., 2004). The light fraction organic matter and particulate organic matter, which are not included in the organo-mineral particles because of their nonassociation with soil minerals, can be removed by density fractionation or acid hydrolysis (Rovira and Vallejo, 2002; Six et al., 2002). Clay and silt particles, with high specific surface area and numerous reaction sites, are crucial to the formation of organo-mineral particles (Caravaca et al., 1999; Eustehues et al., 2003). Organo-mineral particles and some microbial polysaccharides can further form microaggregates by mutual binding (Angers, 1998; Andreu et al., 2001). Presumably, the organo-mineral particles and microaggregates may increase SOC residence time and pool size by reducing the accessibility of microbes to SOC, through chemical complexation and/or physical protection (Powers and Schlesinger, 2002).

\footnotetext{
${ }^{* 1}$ Project supported by the National Natural Science Foundation of China (Nos. 40321101 and 40071036) and the Major State Basic Research Development Program of China (973 Program) (No. 2002CB412503).

${ }^{* 2}$ Corresponding author. E-mail: wangxk@rcees.ac.cn.
} 
Density fractionation can separate soil organic matter into the light and heavy fractions, the latter being mostly in the organo-mineral particles or microaggregates. Not all of the organic matter associated with soil minerals is chemically recalcitrant (Six et al., 2002). For example, some microbial polysaccharides that are not accessible by microorganisms because of their association with mineral surfaces or physical protection inside soil aggregates are chemically labile (McLauchlan and Hobbie, 2004). Therefore, a combination of density fractionation and acid hydrolysis may be useful in assessing the storage of SOC and its stabilization mechanisms.

In the present study, density fractionation and acid hydrolysis were used to assess the spatial variation in SOC, heavy fractions of organic carbon (HFOC), and resistant organic carbon (ROC) in soils of the southern Hulun Buir region, China. The objectives were to identify the dominant factors that affect the spatial variation in SOC, HFOC, and ROC contents in the region and to compare the differences between the HFOC contents derived by density fractionation and the ROC contents obtained by acid hydrolysis.

\section{MATERIALS AND METHODS}

\section{Site description}

Six distinct vegetation patterns exist in the southern Hulun Buir region $\left(47^{\circ} 30^{\prime}-48^{\circ} 30^{\prime} \mathrm{N}\right.$ and $115^{\circ} 31^{\prime}-126^{\circ} 04^{\prime} \mathrm{E}$ ), northeastern China (Fig. 1), and the distance from east to west of this region is about $600 \mathrm{~km}$. In the eastern part are the Daxingan Mountains and in the western part lies the Hulun Buir great steppe. As influenced by the Siberia-Mongolia anticyclone in winter and moist Pacific air masses in summer, the climate varies from warm and moist in the east to cold and dry in the west. The lofty Daxingan Mountains also have some effects on the spatial pattern of the climate, and the highest annual precipitation and the lowest annual mean temperature occur at their summit (Zhang, 1998; Ni and Zhang, 2000). Under the influence of the climate, natural vegetation types from east to west are as follows: oak (Quercus mongolica) forest (OF), larch (Larix gmelini) forest (LF), forest-steppe mosaic (FS), pine (Pinus sylvestris) forest (PF), semi-humid steppe (HS), and semi-arid steppe (AS). OF, on the eastern foothills of the Daxingan Mountains, is deciduous forest. LF represents the southernmost part of the global boreal forest biome (known as the boreal forest) and is distributed in the Daxingan Mountains (Jiang et al., 2002). FS is dominated by birch (Betula pendula) and poplar (Populus deltoides) forest on shaded slopes and by grassland on sunny slopes. PF, on the western foothills of the Daxingan Mountains, is drought-resistant forest. HS is dominated by Stipa grandis and Aneurolepidium chinense,
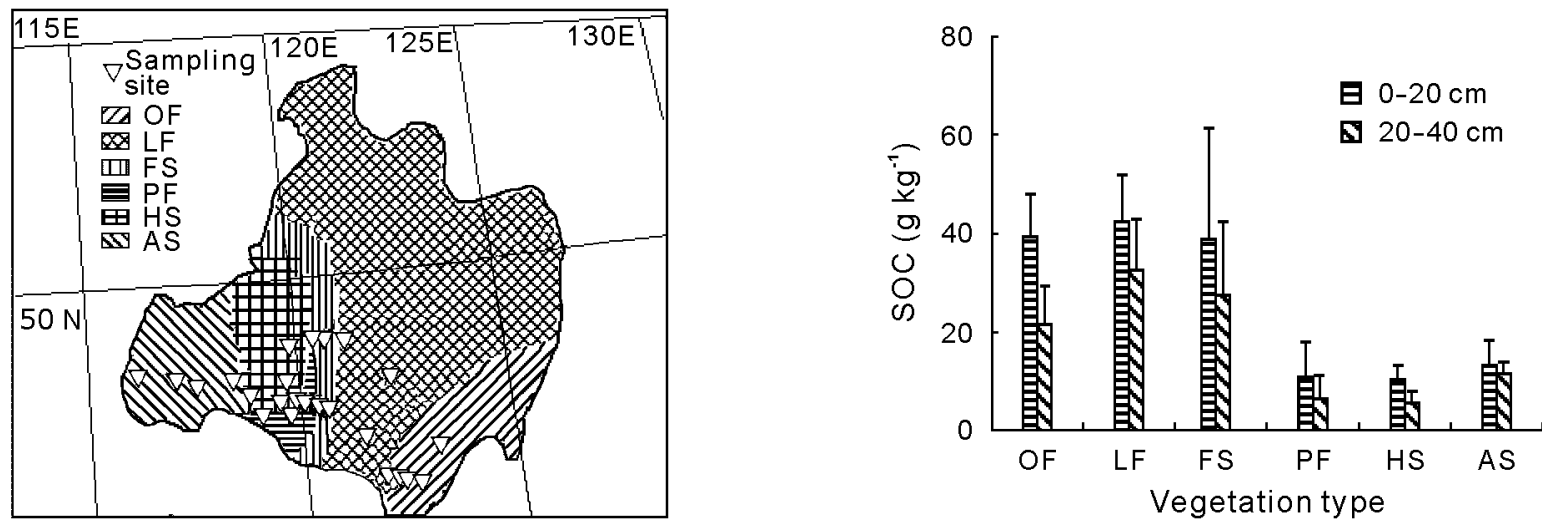

Fig. 1 Vegetation types and sampling sites in the southern Hulunbeier region, China. OF = oak forest; LF = larch forest; FS = forest-steppe; PF = pine forest; HS = semi-humid steppe; AS = semi-arid steppe.

Fig. 2 Soil organic carbon (SOC) contents in the soils under various vegetation types. OF $=$ oak forest; LF $=$ larch forest; FS = forest-steppe; PF = pine forest; HS = semi-humid steppe; AS = semi-arid steppe. 
and AS is dominated by Stipa baicalensis and Aneurolepidium chinense (Wang et al., 1979; Zhou, 1997). Soil types from east to west vary, ranging from dark-brown soils (brown loamy soils) to brown coniferous forest soils (Semi-Pedosols), gray forest soils, aeolian soils, sandy black soils, and chestnut soils (Inner Mongolia Soil Survey Office, 1994).

\section{Soil sampling and analyses}

For each vegetation type, four typical sites were selected and sampled in May 2004. At each site, 10 random soil cores (6 cm diameter) were collected at 0-20 and 20-40 cm depths and mixed into one composite sample for each of the two depths. The soil samples were air-dried and then passed through a $2 \mathrm{~mm}$ sieve before analysis.

To quantify the clay and silt particles $(0-50 \mu \mathrm{m})$, the soil was first oxidized with $\mathrm{H}_{2} \mathrm{O}_{2}$ to remove the organic matter. About $50 \mathrm{~g}$ air-dried soil (passed through $2 \mathrm{~mm}$ sieve) was placed in a $1 \mathrm{~L}$ plastic beaker, $300 \mathrm{~mL} \mathrm{~L}{ }^{-1} \mathrm{H}_{2} \mathrm{O}_{2}$ was gradually added and agitated gently with a glass stick to prevent foaming, and the mixture was subsequently treated in an oven at $60-70{ }^{\circ} \mathrm{C}$ for about $5 \mathrm{~h}$. This process was repeated at least six times. The contents of clay and silt particles were determined in $20 \mathrm{~g} \mathrm{H}_{2} \mathrm{O}_{2}$-treated soil through ultrasonic dispersion, followed by wet-sieving through a $50 \mu \mathrm{m}$ sieve. The residues (fine and coarse sand) were collected, oven-dried at $105{ }^{\circ} \mathrm{C}$, and weighed; the contents of clay and silt particles $(0-50 \mu \mathrm{m})$ were given by the difference in the oven-dried weight between the total $\mathrm{H}_{2} \mathrm{O}_{2}$-treated soil mineral particles $(0-2000 \mu \mathrm{m})$ and the wet-sieved residues $(50-2000 \mu \mathrm{m})$.

The methylene blue (MB) adsorption by soil minerals has been used to quantify the surface reaction sites of soil minerals. It can be used to define the potential binding capacity of soil minerals with humic substances, by the formation of organo-mineral particles (Gürses et al., 2004). In brief, $0.5 \mathrm{~g}$ of the $\mathrm{H}_{2} \mathrm{O}_{2}$-treated soil was placed in a $100 \mathrm{~mL}$ plastic centrifuge tube (duplicate) and $50 \mathrm{~mL}$ aqueous $\mathrm{MB}$ solution $\left(0.2 \mathrm{~g} \mathrm{~L}^{-1}\right)$ was added. The mixed suspension in the centrifuge tube was capped and shaken vigorously (120 times per minute) for $1 \mathrm{~h}$, and then the supernatant was obtained by centrifugation ( 5 min, $\left.3000 \mathrm{r} \mathrm{min}^{-1}\right)$. The content of remaining MB in the supernatant solution was determined with an ultraviolet (UV) spectrophotometer (UNICO, UV-2102 PC) at $666 \mathrm{~nm}$. Finally, the MB adsorption by soil minerals was calculated and expressed as $\mathrm{mg} \mathrm{g}^{-1}$ (Gürses et al., 2004).

Water-stable microaggregates were defined as the clay and silt organo-mineral particles that existed in 50-250 $\mu \mathrm{m}$ soil fractions after $24 \mathrm{~h}$ water saturation. The microaggregates excluded the fine sand and particulate organic matter (iS + POM) in 50-250 $\mu \mathrm{m}$ fractions of the soil (Six et al., 2000). Briefly, $10 \mathrm{~g}$ air-dried soil was placed in a $100 \mathrm{~mL}$ beaker, $50 \mathrm{~mL}$ distilled water was added, the soil remained saturated for $24 \mathrm{~h}$, and then it was carefully wet-sieved through 250 and $50 \mu \mathrm{m}$ sieves sequentially. The materials that passed through the $250 \mu \mathrm{m}$ sieve and remained on the $50 \mu \mathrm{m}$ sieve were collected, oven-dried at $105^{\circ} \mathrm{C}$, and weighed as microaggregates, including the fine sand and particulate organic matter (MA1). Then MA1 was immersed and wet-sieved through a $50 \mu \mathrm{m}$ sieve by agitating with a plastic tip until the water passing through was clear. The material remaining on the $50 \mu \mathrm{m}$ sieve was collected, oven-dried at $105{ }^{\circ} \mathrm{C}$, and weighed as iS + POM. The microaggregate content was calculated as the difference between MA1 and iS + POM.

The contents of SOC, HFOC, and ROC were determined by the Walkey Black method (Lu, 1999). The heavy fractions of organic carbon (HFOC) were obtained by density fractionation. Briefly, $20 \mathrm{~g}$ soil was placed into a $100 \mathrm{~mL}$ plastic centrifuge tube, after which about $50 \mathrm{~mL} 1.59 \mathrm{~g} \mathrm{~mL}^{-1}$ carbon tetrachloride $\left(\mathrm{CCl}_{4}\right)$ was added $(\mathrm{Wu}$ and $\mathrm{Xu}, 2004)$, to remove the lighter parts by shaking and centrifugation (3000 $\mathrm{r} \mathrm{min}^{-1}, 10 \mathrm{~min}$ ). This process was subsequently repeated thrice. Then $25 \mathrm{~mL} 950$ $\mathrm{g} \mathrm{mL}^{-1}$ alcohol (analytical reagent) was used to dissolve the carbon tetrachloride in the tube. Finally, $50 \mathrm{~mL}$ distilled water was used repeatedly to rinse the soil by centrifugation, to remove the carbon tetrachloride and to yield HFOC. The resistant organic carbon fractions (ROC) were obtained by acid hydrolysis, which preferentially removed proteinaceous, polysaccharide-type organic carbon, and other labile organic compounds (Eustehues et al., 2003). Briefly, about $20 \mathrm{~g}$ of air-dried soil was placed in a 
$100 \mathrm{~mL}$ glass tube with addition of 30-40 $\mathrm{mL} 6 \mathrm{~mol} \mathrm{~L}^{-1} \mathrm{HCl}$. The tube capped with a glass funnel was then placed in an oven at $80^{\circ} \mathrm{C}$ for $24 \mathrm{~h}$ and shaken gently at $5-8 \mathrm{~h}$ intervals until the visible organic particulates disappeared. Next, distilled water was used repeatedly to wash the soil, to remove the excess $\mathrm{HCl}$ by centrifugation, and the solids were oven-dried at $50{ }^{\circ} \mathrm{C}$ to yield ROC. Differences in SOC, HFOC, and ROC contents between vegetation types were first tested by a one-way analysis of variance (ANOVA). The SOC, HFOC, and ROC mean values among vegetation types were then compared with the least significant difference (LSD) method (post hoc test) (SPSS 10.0).

\section{RESULTS}

\section{Soil texture, MB adsorption, and microaggregates}

The clay and silt particle content, the microaggregate content, and the MB adsorption by soil minerals varied among the sampling sites and vegetation types (Table I). Generally, higher contents of clay and silt particles were found in OF, BF, and FS than in PF, HS, and AS. The higher the clay and silt particle content, the higher the MB adsorption by soil minerals and microaggregate content $(P<0.05)$ (Table II). The MB adsorption by soil minerals and the clay and silt particle content in the $20-40 \mathrm{~cm}$ layer were similar to those in the $0-20 \mathrm{~cm}$ layer, whereas most of the values of the microaggregates in the 20-40 $\mathrm{cm}$ soil layer were lower than those in the 0-20 $\mathrm{cm}$ soil layer.

\section{TABLE I}

Some physical properties of the $0-20$ and $20-40 \mathrm{~cm}$ soil layers under various vegetation types

\begin{tabular}{|c|c|c|c|c|c|c|c|}
\hline \multirow[t]{2}{*}{$\begin{array}{l}\text { Vegetation } \\
\text { Type }^{\text {a) }}\end{array}$} & \multirow[t]{2}{*}{$\begin{array}{l}\text { Sampling } \\
\text { site }\end{array}$} & \multicolumn{2}{|c|}{$\begin{array}{l}\text { Clay and silt particles } \\
(0-50 \mu \mathrm{m})\end{array}$} & \multicolumn{2}{|c|}{$\begin{array}{l}\text { Microaggregates (50-250 } \\
\mu \mathrm{m})\end{array}$} & \multicolumn{2}{|c|}{$\begin{array}{l}\text { Methylene blue adsorption } \\
\text { by soil minerals }\end{array}$} \\
\hline & & $0-20 \mathrm{~cm}$ & $20-40 \mathrm{~cm}$ & $0-20 \mathrm{~cm}$ & $20-40 \mathrm{~cm}$ & $0-20 \mathrm{~cm}$ & $20-40 \mathrm{~cm}$ \\
\hline & & $-\mathrm{g}$ & & & $\mathrm{m}$ & & \\
\hline \multirow[t]{4}{*}{$\mathrm{OF}$} & 1 & 700.5 & 723.5 & 420.7 & 280.7 & 20.32 & 20.36 \\
\hline & 2 & 643.5 & 562.0 & 310.1 & 172.7 & 21.32 & 21.98 \\
\hline & 3 & 778.0 & 784.5 & 443.8 & 399.9 & 24.93 & 25.84 \\
\hline & 4 & 873.5 & 862.0 & 411.6 & 350.6 & 31.62 & 35.87 \\
\hline \multirow[t]{4}{*}{ LF } & 1 & 812.0 & 803.5 & 426.5 & 429.5 & 34.80 & 35.84 \\
\hline & 2 & 861.0 & 869.5 & 439.3 & 417.7 & 34.55 & 34.69 \\
\hline & 3 & 864.5 & 873.5 & 420.6 & 380.9 & 36.49 & 35.04 \\
\hline & 4 & 812.5 & 821.0 & 363.4 & 253.7 & 24.81 & 24.29 \\
\hline \multirow[t]{4}{*}{ FS } & 1 & 554.0 & 532.0 & 329.2 & 278.6 & 19.49 & 19.84 \\
\hline & 2 & 885.5 & 873.0 & 417.5 & 379.9 & 24.02 & 24.07 \\
\hline & 3 & 701.0 & 690.5 & 368.2 & 355.7 & 25.39 & 25.25 \\
\hline & 4 & 241.0 & 226.0 & 52.6 & 26.3 & 9.48 & 8.74 \\
\hline \multirow[t]{4}{*}{$\mathrm{PF}$} & 1 & 24.5 & 18.5 & 19.5 & 13.5 & 2.36 & 2.38 \\
\hline & 2 & 157.5 & 122.0 & 71.9 & 51.5 & 6.58 & 6.32 \\
\hline & 3 & 223.0 & 171.0 & 122.6 & 120.3 & 9.65 & 9.42 \\
\hline & 4 & 168.0 & 155.5 & 56.7 & 43.1 & 8.42 & 8.45 \\
\hline \multirow[t]{4}{*}{ HS } & 1 & 223.5 & 345.5 & 146.6 & 186.5 & 4.83 & 4.98 \\
\hline & 2 & 180.0 & 162.0 & 63.7 & 15.1 & 9.01 & 8.99 \\
\hline & 3 & 55.0 & 21.0 & 42.3 & 18.0 & 2.44 & 2.32 \\
\hline & 4 & 238.5 & 235.5 & 114.6 & 80.3 & 3.26 & 3.26 \\
\hline \multirow[t]{4}{*}{ AS } & 1 & 291.0 & 340.5 & 199.0 & 228.2 & 13.19 & 15.43 \\
\hline & 2 & 196.5 & 226.0 & 85.2 & 83.6 & 12.47 & 14.10 \\
\hline & 3 & 438.5 & 522.0 & 296.6 & 178.1 & 13.19 & 17.45 \\
\hline & 4 & 276.5 & 294.0 & 137.4 & 120.4 & 13.33 & 11.06 \\
\hline
\end{tabular}

a) $\mathrm{OF}=$ oak forest; $\mathrm{LF}=$ larch forest; FS = forest-steppe; $\mathrm{PF}=$ pine forest; HS = semi-humid steppe; AS = semi-arid steppe. 
TABLE II

Correlations among the soil organic carbon (SOC), heavy fraction organic carbon (HFOC), resistant organic carbon (ROC), clay and silt particles (CSP), methylene blue adsorption by soil minerals (MBA), and microaggregates (MA) in the $0-20$ and $20-40 \mathrm{~cm}$ soil layers $(n=24)$

\begin{tabular}{|c|c|c|c|c|c|c|c|c|c|c|c|c|}
\hline & \multicolumn{12}{|c|}{ Soil layer } \\
\hline & \multicolumn{6}{|l|}{$0-20 \mathrm{~cm}$} & \multicolumn{6}{|c|}{$20-40 \mathrm{~cm}$} \\
\hline & $\mathrm{SOC}$ & HFOC & $\mathrm{ROC}$ & MBA & CSP & MA & $\mathrm{SOC}$ & HFOC & $\mathrm{ROC}$ & MBA & CSP & MA \\
\hline $\mathrm{SOC}$ & 1.000 & & & & & & 1.000 & & & & & \\
\hline HFOC & $0.998^{* *}$ & 1.000 & & & & & $0.992^{* *}$ & 1.000 & & & & \\
\hline $\mathrm{ROC}$ & $0.981^{* *}$ & $0.981^{* *}$ & 1.000 & & & & $0.985^{* *}$ & $0.992 * *$ & 1.000 & & & \\
\hline MBA & $0.837 * *$ & $0.840^{* *}$ & $0.785^{* *}$ & 1.000 & & & $0.816^{* *}$ & $0.795^{* *}$ & $0.799 * *$ & 1.000 & & \\
\hline CSP & $0.915 * *$ & $0.918^{* *}$ & $0.862^{* *}$ & $0.945^{* *}$ & 1.000 & & $0.855^{* *}$ & $0.851^{* *}$ & $0.858^{* *}$ & $0.932^{* *}$ & 1.000 & \\
\hline MA & $0.909 * *$ & $0.905^{* *}$ & $0.864^{* *}$ & $0.909 * *$ & $0.973^{* *}$ & 1.000 & $0.876^{* *}$ & $0.870^{* *}$ & $0.872^{* *}$ & $0.908^{* *}$ & $0.941 * *$ & 1.000 \\
\hline
\end{tabular}

** Significant at the 0.01 level.

\section{$S O C, H F O C$, and $R O C$ contents}

Significant differences were found in SOC contents among vegetation types in the $0-20$ and 20-40 cm soil layers $(P<0.05)$ (Fig. 2). SOC contents ranged from 2.1 to $66.6 \mathrm{~g} \mathrm{~kg}^{-1}$ in the $0-20 \mathrm{~cm}$ layer and from 0.8 to $46.1 \mathrm{~g} \mathrm{~kg}^{-1}$ in the $20-40 \mathrm{~cm}$ layer. In the $0-20 \mathrm{~cm}$ soil layer, SOC contents in the eastern part of the region (OF, LF, and FS) ranged from 11.9 to $66.6 \mathrm{~g} \mathrm{~kg}^{-1}$, being 2-3 times higher than those in the west part $(\mathrm{PF}, \mathrm{HS}$, and AS) $(P<0.05)$. Similarly, mean SOC contents in the $20-40 \mathrm{~cm}$ soil layer in LF and FS were approximately twice those in PF, HS, and AS. Although the mean SOC in the 20-40 $\mathrm{cm}$ layer in OF was higher than those in PF and HS $(P<0.05)$, it was similar to that in AS $(P>0.05)$.

The HFOC pool that is mostly associated with soil minerals was the major SOC component, accounting for 75\%-95\% of the SOC (Figs. 2 and 3). The variation in HFOC among vegetation types followed the same pattern as the SOC $(P<0.05)$ (Fig. 3). HFOC contents ranged mostly from 1.8 to $65.0 \mathrm{~g} \mathrm{~kg}^{-1}$ in the $0-20 \mathrm{~cm}$ layer and from 0.7 to $45.8 \mathrm{~g} \mathrm{~kg}^{-1}$ in the $20-40 \mathrm{~cm}$ layer. Generally, HFOC contents in the eastern part (OF, LF, and FS) were higher than those in the west part (PF, HS, and AS). The HFOC contents in the 20-40 cm layer were lower than those in the 0-20 cm layer.
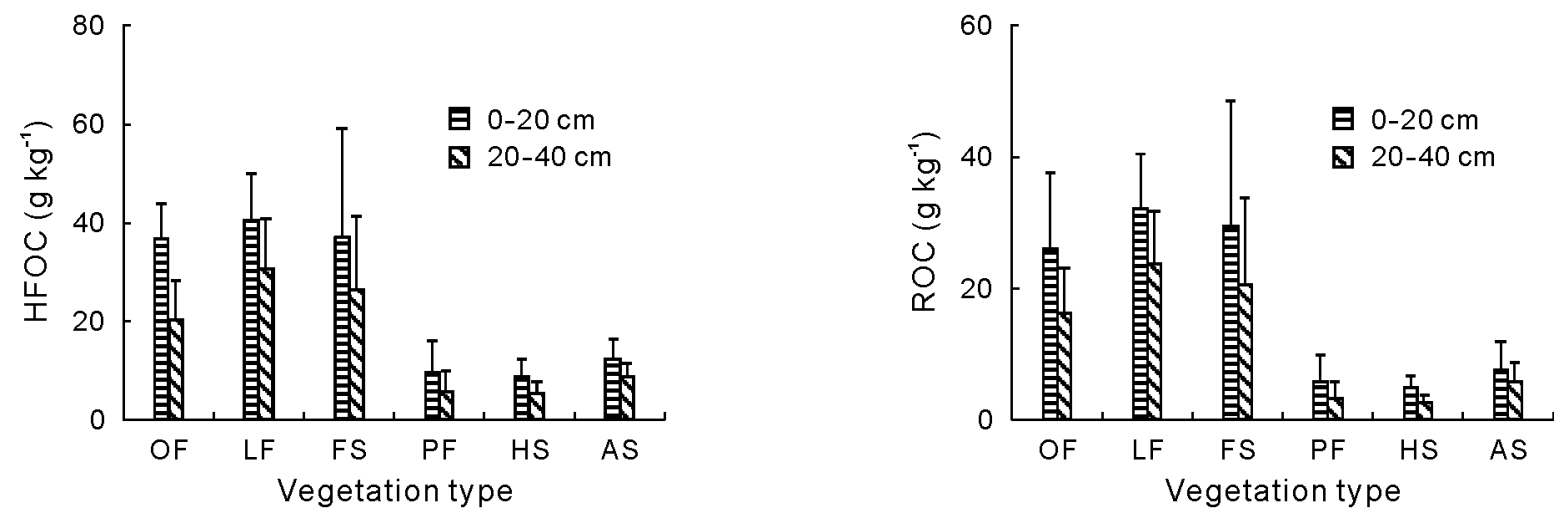

Fig. 3 Heavy fraction organic carbon (HFOC) contents in the soils under various vegetation types. OF = oak forest; LF $=$ larch forest; $\mathrm{FS}=$ forest-steppe; $\mathrm{PF}=$ pine forest; $\mathrm{HS}=$ semi-humid steppe; $\mathrm{AS}=$ semi-arid steppe.

Fig. 4 Resistant organic carbon (ROC) contents in the soils under various vegetation types. OF = oak forest; LF $=$ larch forest; FS = forest-steppe; PF = pine forest; HS = semi-humid steppe; AS = semi-arid steppe.

Significant differences were observed in ROC among vegetation types at soil depths of 0-20 and $20-40 \mathrm{~cm}(P<0.05)(\mathrm{Fig} 4)$. ROC contents ranged from 0.7 to $54.4 \mathrm{~g} \mathrm{~kg}^{-1}$ in the $0-20 \mathrm{~cm}$ layer and 
from 0.3 to $37.3 \mathrm{~g} \mathrm{~kg}^{-1}$ in the $20-40 \mathrm{~cm}$ layer. The proportions of ROC to SOC were $25 \%-83 \%$ (Figs. 2 and 4). The spatial variation in ROC content was similar to that of SOC. Mean values of ROC in the eastern part (OF, LF, and FS) were 2-3 times higher than those in the west part (PF, HS, and AS).

Relations of SOC, HFOC, and ROC to clay and silt particles, MB adsorption, and microaggregates

The HFOC pool or ROC pool was the major part of SOC content, and the HFOC or ROC content was significantly $(P<0.01)$ correlated to the SOC content (Table II). In the 0-20 cm layer, SOC, HFOC, and ROC contents were significantly $(P<0.01)$ positively correlated with MB adsorption, clay and silt particle content, and microaggregate content (Table II). Similar relationships were found in the 20-40 cm soil layer (Table II). These significant relationships indicated that MB adsorption, clay and silt particle content, and microaggregate content were important factors influencing the spatial variation of SOC, HFOC, and ROC contents in the southern Hulun Buir region.

\section{DISCUSSION}

It has been widely recognized that the spatial variability of SOC content is influenced by factors including climate, land cover, and soil texture (Peng et al., 2004). The higher heterogeneity of SOC content on account of changes in land cover or climatic condition in northeast China has been reported elsewhere (Sun et al., 2004; Xie et al., 2004). According to Xie et al. (2004), the increasing trend in SOC content from west to east in the northern part of China is primarily associated with the increase in precipitation and the change of land cover. This trend also apparently occurred in the present study. Meanwhile, the soil texture may be an important factor influencing the spatial variation of SOC contents in the southern Hulun Buir region. The higher contents of clay and silt particles occurred in OF, LF, and FS where soils were derived from granite and arenose rock (Table I). Lower contents of clay and silt particles occurred in HS and AS where the soils formed from flooding sand and sediments (Zhang, 1998) and where the weathering rate was low owing to the arid climate. Therefore, SOC, HFOC, and ROC contents were lower in the west part (PF, HS, and AS) than in the east part (OF, LF, and FS) (Figs. 2-4). Higher clay and silt contents tend to form more organo-mineral particles and aggregates, which increases the HFOC and ROC contents (Chaney and Swift, 1986; Angers, 1998; Zhang and Horn, 2001).

HFOC and ROC contents have been widely used to interpret the stabilization mechanism of soil organic carbon (Eustehues et al., 2003; Wu and Xu, 2004). Generally, the HFOC content determined by density fractionation was slightly higher than the ROC content determined by acid hydrolysis (Figs. 3 and 4). Conventionally, the density fractionation method can only remove the free light particulate organic matter that is not occluded in the microaggregates (Angers, 1998; Peng et al., 2004). Some labile enzymes, microorganisms or aggregate-forming polysaccharides are still preserved in the heavy organic matter or on the surface of the microaggregates (Huang et al., 2003; Taubaso et al., 2004). However, the acid hydrolysis method can largely remove the labile components mentioned above, and the residues (ROC) are the chemically recalcitrant organic carbon (Six et al., 2002). Hence, density fractionation or acid hydrolysis should be used with caution when studying the mechanisms of soil organic carbon stabilization.

In conclusion, significant differences were observed in the SOC, HFOC, and ROC contents among vegetation types within each soil layer (0-20 and 20-40 cm). The SOC, HFOC, and ROC contents in LF and FS were significantly higher than those in PF, HS, and AS $(P<0.05)$. Meanwhile, SOC, HFOC, and ROC contents positively increased with clay and silt particles, the MB adsorption by soil minerals, and microaggregate abundance, suggesting that soil texture, the MB adsorption by soil minerals or microaggregate abundance might be important in the spatial variation of soil carbon content and its stability. 


\section{ACKNOWLEDGMENTS}

The authors thank Academician Feng Zong-Wei, Research Center for Eco-Environmental Sciences, Chinese Academy of Sciences, who proposed this study. Without his guidance and kindness, this study could not have been finished so quickly. Thanks to Dr. Erich W. Schienke, Rensselaer Polytechnic Institute, and Shuijin Wu, North Carolina State University, for the correction of this manuscript.

\section{REFERENCES}

Andreu, V., Imenson, A. C. and Rubio, J. L. 2001. Temporal changes in soil aggregates and water erosion after a wildfire in a Mediterranean pine forest. Catena. 44: 69-84.

Angers, D. A. 1998. Water-stable aggregation of Québec silty clay soils: some factors controlling its dynamics. Soil Till. Res. 47: 91-96.

Caravaca, F., Lax, A. and Albaladejo, J. 1999. Organic matter, nutrient contents and cation exchange capacity in fine fractions from semiarid calcareous soils. Geoderma. 93: 161-176.

Chaney, K. and Swift, R. S. 1986. Studies on aggregate stability: II. The effect of humic substances on the stability of re-formed soil aggregates. J. Soil Sci. 37: 337-343.

Eustehues, K., Rumpel, C., Kleber, M. and Kögel-Knaber, I. 2003. Stabilisation of soil organic matter by interactions with minerals revealed by mineral dissolution and oxidative degradation. Org. Geochem. 34: 1591-1600.

Gürses, A., Karaca, Ç., Doğar, C., Bayrak, R., Açikildiz, M. and Yalçın, M. 2004. Determination of adsorptive properties of clay/water system: methylene blue sorption. J. Colloid Interf. Sci. 269: 310-314.

Huang, Q. Y., Zhao, Z. H. and Chen, W. L. 2003. Effects of several low-molecular weight organic acids and phosphate on the adsorption of acid phosphatase by soil colloids and minerals. Chemosphere. 52: 571-579.

Inner Mongolia Soil Survey Office. 1994. Soils in Inner Mongolia (in Chinese). Science Press, Beijing.

Jiang, H., Apps, M. J., Peng, C. H., Zhang, Y. L. and Liu, J. X. 2002. Modelling the influence of harvesting on Chinese boreal forest carbon dynamics. Forest Ecol. Manag. 169: 65-82.

Lu, R. K. 1999. Analytical Methods for Soil and Agricultural Chemistry (in Chinese). Agriculture Science and Technology Press, Beijing.

Mann, L. K. 1986. Changes in soil carbon storage after cultivation. Soil Sci. 142(5): 279-288.

McLauchlan, K. K. and Hobbie, S. E. 2004. Comparison of labile soil organic matter fractionation techniques. Soil Sci. Soc. Am. J. 68: 1616-1625.

Ni, J. and Zhang, X. S. 2000. Climate variability, ecological gradient and the northeast China transect (NECT). J. Arid Environ. 46: 313-325.

O'Brien, N. D., Attiwill, P. M. and Weston, C. J. 2003. Stability of soil organic matter in Eucalyptus regnans forests and Pinus radiata plantations in south eastern Australia. Forest Ecol. Manag. 185: 249-261.

Peng, X. H., Zhang, B. and Zhao, Q. G. 2004. A review on relationship between soil organic carbon pools and soil structure stability. Acta Pedol. Sin. (in Chinese). 41: 618-623.

Powers, J. S. and Schlesinger, W. H. 2002. Relationships among soil carbon distributions and biophysical factors at nested spatial scales in rain forests of northeastern Costa Rica. Geoderma. 109: 165-190.

Rovira, P. and Vallejo, V. R. 2002. Labile and recalcitrant pools of carbon and nitrogen in organic matter decomposing at different depths in soil: an acid hydrolysis approach. Geoderma. 107: 109-141.

Six, J., Conant, R. T., Paul, E. A. and Paustian, K. 2002. Stabilization mechanisms of soil organic matter: Implications for C-saturation of soils. Plant Soil. 241: 155-176.

Six, J., Elliott, E. T. and Paustain, K. 2000. Soil macroaggregate turnover and microaggregate formation: A mechanism for C sequestration under no-tillage agriculture. Soil Biol. Biochem. 32: 2 099-2 103.

Sun, W. X., Shi, X. Z., Yu, D. S., Wang, K. and Wang, H. J. 2004. Estimation of soil organic carbon density and storage of northeast China. Acta Pedol. Sin. (in Chinese). 41: 298-300.

Taubaso, C., dos Santos Afonsoa, M. and Torres Sánchezb, R. M. 2004. Modelling soil surface charge density using mineral composition. Geoderma. 121: 123-133.

Wang, Y. F., Yong, S. P. and Liu, Z. L. 1979. Characteristics of the vegetational zones in Inner Monggol Autonomous Region. Acta Bot. Sin. (in Chinese). 21(3): 276-283.

Wu, J. G. and Xu, D. Y. 2004. The Effects of Landuse Change on the Soil Organic Carbon-Theory, Methods and Practice (in Chinese). China Forestry Press, Beijing.

Xie, X. L., Sun, B., Zhou, H. Z. and Li, A. B. 2004. soil organic carbon storage in China. Pedosphere. 14: 491-500.

Zhang, B. and Horn, R. 2001. Mechanisms of aggregate stabilization in Ultisols from subtropical China. Geoderma. 99: $123-145$.

Zhang, D. P. 1998. The Reference of the Minerals Resources Exploration in Hulun Buir League (in Chinese). Geological Press, Beijing.

Zhou, Y. L. 1997. Geography of the Vegetations in Northeast China (in Chinese). Science Press, Beijing. 